\title{
Strain-induced formation of ultrathin mixed-oxide films
}

\author{
Xiang Shao, ${ }^{1}$ Niklas Nilius, ${ }^{1,}$ Philipp Myrach, ${ }^{1}$ Hans-Joachim Freund, ${ }^{1}$ Umberto Martinez, ${ }^{2}$ Stefano Prada, ${ }^{2}$ \\ Livia Giordano, ${ }^{2}$ and Gianfranco Pacchioni ${ }^{2, \dagger}$ \\ ${ }^{1}$ Fritz-Haber-Institut der Max-Planck-Gesellschaft, Faradayweg 4-6, D-14195 Berlin, Germany \\ ${ }^{2}$ Dipartimento di Scienza dei Materiali, Università di Milano-Bicocca, via Cozzi 53, I-20125 Milano, Italy
}

(Received 23 December 2010; revised manuscript received 11 March 2011; published 20 June 2011)

\begin{abstract}
By means of scanning tunneling microscopy, Auger spectroscopy, and density-functional theory, we have identified a different strain-relaxation mechanism taking place in ultrathin $\mathrm{CaO}$ films grown on $\mathrm{Mo}(001)$. Whereas $\mathrm{CaO}$ films are amorphous at low growth temperature due to the substantial lattice mismatch with the support, a crystalline phase develops upon annealing to $1000 \mathrm{~K}$. This phase is characterized by a sharp $(2 \times 2)$ pattern in low-energy electron diffraction and displays wide, atomically flat terraces in scanning tunneling microscopy images. The phase transition is initiated by the diffusion of Mo from the support into the film, where it replaces $25 \%$ of the $\mathrm{Ca}$ ions. The resulting rocksalt-type $\mathrm{Ca}_{3} \mathrm{MoO}_{4}$ structure has a negligible lattice mismatch with the Mo(001), enabling the growth of extended, defect-free oxide patches. The oxidation of Mo atoms from the support provides the thermodynamic stimulus for the phase transition. For $\mathrm{MgO}$ films grown on the same $\mathrm{Mo}(001)$ surface, no relevant intermixing is revealed at the interface, most likely because of the smaller lattice mismatch between both systems.
\end{abstract}

DOI: 10.1103/PhysRevB.83.245407 PACS number(s): 68.55.A-, 68.47.Gh, 68.37.Ef, 71.15.Mb

\section{INTRODUCTION}

The growth of thin oxide films on metal supports has developed into a versatile and powerful approach to investigate metal-oxide interactions at the atomic level, as evidenced by the large number of recent publications in this field. ${ }^{1-4}$ Two unique properties make thin-film systems so fascinating for surface and material science as well as for catalysis research. On the one hand, thin films might be considered as the "electrically conductive" counterpart of wide-gap and hence insulating bulk oxides. They can thus be investigated with classical surface science techniques, as charge transport through the film remains possible via electron tunneling. On the other hand, ultrathin oxide films on metal supports turned out to be an interesting material combination in their own right, as they possess properties that are intrinsically connected with interfacial interactions between both systems. Fascinating consequences of this interplay are charge-transfer processes through the oxide film, ${ }^{5}$ the development of built-in electric fields, ${ }^{6}$ work-function modulations, ${ }^{7}$ and a higher structural flexibility of the oxide lattice. ${ }^{8}$ Moreover, the distinct physical properties of oxide films might be associated with a new chemistry, which opens a route to prepare catalytically relevant systems based on thin-film technology. ${ }^{9}$

The growth of crystalline, atomically flat and stoichiometric oxide layers depends on a number of structural and thermodynamic preconditions. The most important one is a good lattice match between the metal surface and the oxide film, which forms the basis for the development of an epitaxial network of interfacial metal-oxygen bonds. ${ }^{1,2,10}$ Other factors are the electronegativity of the support that controls chargetransfer processes, ${ }^{11,12}$ the metal affinity toward oxygen and its thermal stability, defining the maximum temperature to equilibrate the system. Structural flexibility of the thin film is another important parameter, as it determines the ability of the overlayer to compensate misfit-induced lattice strain. Several strain-relaxation mechanisms have been identified for metal-oxide interfaces. The most prominent ones are plastic lattice deformations, e.g., misfit dislocations, grain boundaries, and mosaics. ${ }^{13,14}$ The presence of line defects is, however, incompatible with many applications of thin-film systems, as they alter the electronic and chemical nature of the film and open communication channels with the metal below. Alternative relaxation mechanisms rely on modifications of the stoichiometry and crystal structure of the oxide film. NiO, for example, was found to develop an oxygen-poor interface structure, which better matches the lattice constant of the $\mathrm{Pd}(100)$ support. ${ }^{15}$ Other films, such as $\mathrm{Al}_{10} \mathrm{O}_{13},{ }^{16} \mathrm{Pd}_{4} \mathrm{O}_{5},{ }^{17}$ $\mathrm{TiO}_{x},{ }^{18}$ and $\mathrm{ZnO}$ films,${ }^{19}$ adapt crystal phases that are unknown for the respective bulk materials and only stabilized by the metal surface underneath. Common to all those mechanisms is their self-terminating nature, which means the oxide growth stops at a critical thickness because the thin-film phase cannot be transformed into a bulk structure.

In this paper, we discuss a yet unknown principle for strain relaxation in a thin oxide film. A good lattice match with the metal below is hereby achieved by incorporating substrate ions into the oxide overlayer, which is demonstrated for $\mathrm{CaO}$ deposited onto a $\mathrm{Mo}(001)$ surface. Upon annealing, a well-ordered ternary Ca-Mo-O phase forms that has a similar lattice parameter as the substrate and consequently grows in a pseudomorphic fashion. In contrast, the comparable $\mathrm{MgO} / \mathrm{Mo}(001)$ system remains phase separated even at high temperature, because the strain-induced stimulus for interfacial mixing is much smaller.

\section{EXPERIMENT AND THEORY}

The experiments have been performed in an ultrahigh vacuum chamber equipped with a liquid-nitrogen-cooled scanning tunneling microscope (STM) and a low-energy electron diffraction (LEED)/Auger unit for chemical analysis. The $\mathrm{Mo}(001)$ substrate is cleaned by $\mathrm{Ar}^{+}$sputtering, annealing in oxygen and flashing to $2000 \mathrm{~K}$. Ca and $\mathrm{Mg}$ are vapor deposited onto the clean Mo surface in an $\mathrm{O}_{2}$ ambience of $5 \times 10^{-7} \mathrm{mbar}$ at room temperature. The as-grown oxide 

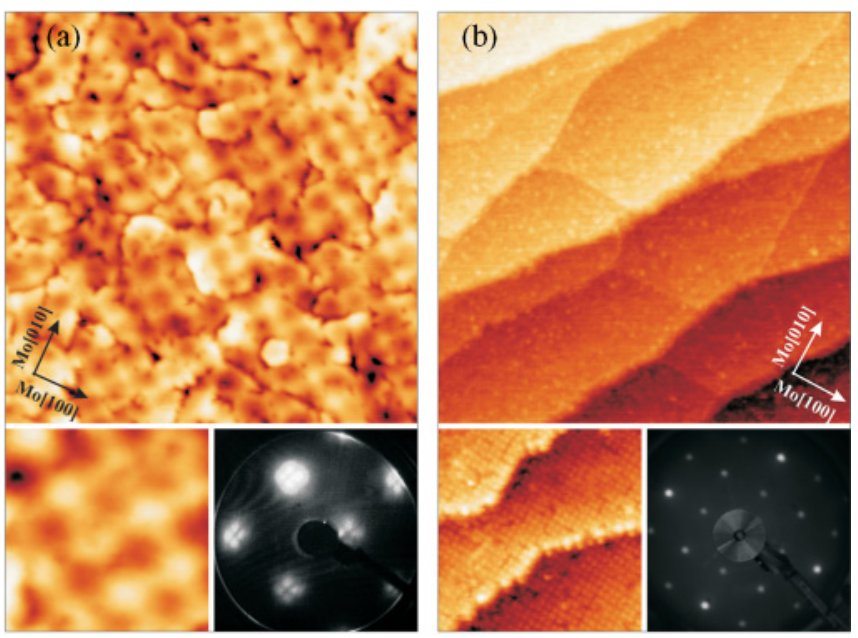

FIG. 1. (Color online) Overview $\left(70 \times 70 \mathrm{~nm}^{2}\right)$ and close-up $\left(17 \times 17 \mathrm{~nm}^{2}\right)$ STM images of (a) 3-ML Mg and (b) 3-ML Ca grown in an $\mathrm{O}_{2}$ atmosphere on $\mathrm{Mo}(001)$ and annealed to $1000 \mathrm{~K}\left(U_{s}=\right.$ $\left.3.0 \mathrm{~V}, I_{t}=50 \mathrm{pA}\right)$. The right panels display the corresponding LEED patterns taken at $75-\mathrm{eV}$ electron energy.

films are stoichiometric, but amorphous as inferred from the absence of any LEED spots. Crystallization can be induced by vacuum annealing to temperatures as high as $1150 \mathrm{~K}$. To analyze the thermodynamic stability of the resulting oxide phases, spin-polarized density-functional theory (DFT) calculations have been performed with the VASP code, ${ }^{20}$ using the generalized gradient approximation, the PW91 exchangecorrelation functional, ${ }^{21}$ a plane-wave basis set with $400 \mathrm{eV}$ energy cutoff, and the projector augmented wave method. ${ }^{22,23}$ The films are modeled with $(2 \times 2)$ supercells containing three to four oxide and four Mo layers, separated by $10 \AA$ of vacuum from the next slab.

\section{RESULTS AND DISCUSSION}

Figure 1 provides information on the structure and morphology of 3-4 monolayer (ML)-thick $\mathrm{MgO}$ and $\mathrm{CaO}$ films annealed to $1000 \mathrm{~K}$. Both films are atomically flat and cover completely the Mo surface. Close-up STM images of the $\mathrm{MgO} / \mathrm{Mo}$ system reveal a regular square pattern with $55 \AA$ periodicity, as described in earlier publications [Fig. 1(a)]. ${ }^{14}$ It is assigned to a coincidence lattice with $19 \mathrm{MgO}$ unit cells overgrowing 18 Mo cells, whereby the $\mathrm{MgO}[110]$ direction aligns with the Mo[100]. The contrast modulation in the STM originates from a different stacking sequence at the interface. ${ }^{24,25}$ The energetically favored structure with O sitting above the Mo atoms appears dark, whereas the Mg-Mo stacking regions show up with bright contrast due to an enlarged interfacial distance. The coincidence lattice develops in order to compensate the $-5.3 \%$ lattice mismatch between bulk $\mathrm{MgO}\left(d_{\mathrm{O}-\mathrm{O}}=2.98 \AA\right)$ and $\mathrm{Mo}(001)\left(d_{\mathrm{Mo}-\mathrm{Mo}}=\right.$ $3.15 \AA$ ) and removes $90 \%$ of the initial misfit strain. The remaining strain is released in the form of grain boundaries and dislocation lines that appear as dark lines in the STM images [Fig. 1(a)]. The proposed relaxation mechanism is in line with the LEED pattern of the 4-ML MgO/Mo(001) film, in which each fundamental spot is split into four satellites.
Those satellites reflect a certain faceting of the surface, arising from the alternation of $\mathrm{O}-\mathrm{Mo}$ and $\mathrm{Mg}$-Mo stacking domains in the film. ${ }^{14}$ The coincidence lattice, on the other hand, is not resolved in reciprocal space due to the limited coherence length of our LEED system.

For $\mathrm{CaO}$ films $\left(d_{\mathrm{O}-\mathrm{O}}=3.4 \AA\right)$, even more pronounced relaxation effects are expected due to the $+8.1 \%$ lattice mismatch with the Mo(001). However, the anticipated low structural quality of the film is not revealed in the experiments [Fig. 1(b)]. The STM images display wide terraces covered with a perfect $6.3 \times 6.3 \AA^{2}$ square lattice that corresponds to a $(2 \times 2)$ superstructure with respect to $\mathrm{Mo}(001)$. The height of the lattice maxima amounts to $0.8 \AA$ and depends only weakly on the applied sample bias. Apart from Mo-induced step edges, no line defects are detected, which is in sharp contrast to the $\mathrm{MgO} / \mathrm{Mo}$ system. The high structural quality of the film becomes manifest also in a perfect $(2 \times 2)$ LEED pattern that shows no sign of disorder or faceting. Apparently, annealed $\mathrm{CaO}$ films are commensurate with the Mo support and therefore display an extremely low defect density. This unexpected finding raises the question on the strain-relaxation mechanism in this heavily mismatched metal-oxide system.

Elastic and plastic deformations of the $\mathrm{CaO}$ lattice are ruled out as possible means to compensate the lattice mismatch. Whereas unreasonably high energies are required to elastically compress the rocksalt lattice towards registry with the Mo, the "plastic route" is discarded because neither a defect network nor a coincidence structure is observed in the experiment. Furthermore, none of those mechanisms would explain the $(2 \times 2)$ superstructure, as the $\mathrm{Mo}(001)$ and the $\mathrm{CaO}(001)$ unit cells have comparable dimensions and should rather induce a $(1 \times 1)$ pattern. We have therefore considered alternative oxide cells that have square symmetry, but a two times larger in-plane lattice parameter. Those new building blocks may differ in their atomic structure and/or stoichiometry from classical rocksalt $\mathrm{CaO}$.

To analyze the film stoichiometry first, we have performed Auger spectroscopy at $45^{\circ}$ incidence angle (Fig. 2). A reference spectrum was obtained for a 25 -ML-thick $\mathrm{CaO} / \mathrm{Mo}$ film prepared at room temperature and postannealed to $1100 \mathrm{~K}$. As expected, only $\mathrm{Ca}$ and $\mathrm{O}$ peaks at 250, 290 and $510 \mathrm{eV}$,
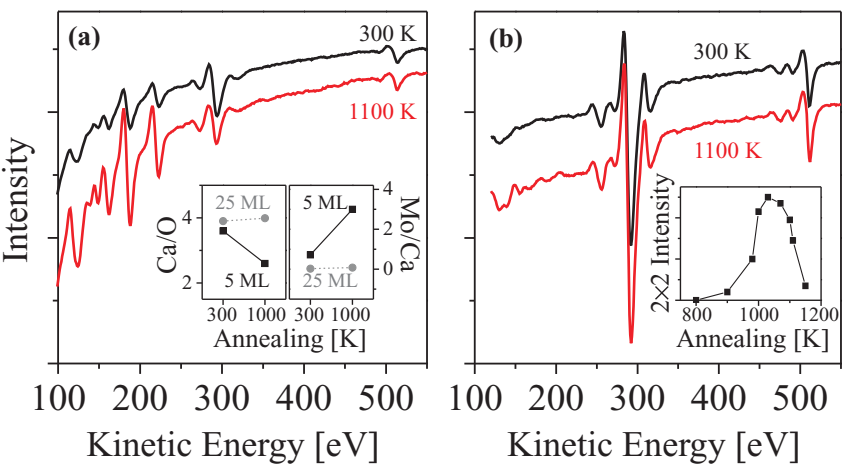

FIG. 2. (Color online) (a) Auger spectra of 5-ML-thick CaO films before (black) and after (red) annealing to $1100 \mathrm{~K}$. (b) Same data for a 25-ML-thick film. Insets (a) and (b) display the development of the $\mathrm{Ca} / \mathrm{O}$ and $\mathrm{Mo} / \mathrm{Ca}$ peak ratios as well as the intensity course of the $(2 \times 2)$ LEED spots upon annealing. 
respectively, are observed for thick films and the Mo signature is completely suppressed. The intensity ratio of the two peaks amounts to $(3.9 \pm 0.1)$ and is identical for as-grown and annealed samples. This $\mathrm{Ca} / \mathrm{O}$ peak ratio is therefore taken as a fingerprint for stoichiomtric $\mathrm{CaO}$. On 3-4-ML films, the Mo Auger transitions at 160, 190, and $220 \mathrm{eV}$ become visible as well, in agreement with the free mean path of electrons in bulk $\mathrm{CaO}$. The as-grown films are still characterized by a $\mathrm{Ca} / \mathrm{O}$ ratio of 3.7, indicative for a one-to-one stoichiometry, but absolute peak intensities are smaller. This ratio gradually declines to 3.6 when annealing the sample to $900 \mathrm{~K}$ and undergoes a sudden drop to 2.6 at $1000 \mathrm{~K}$. Similarly, the Mo signal increases slowly until $900 \mathrm{~K}$, but rises sharply for annealing temperatures above $1000 \mathrm{~K}$. This temperature-dependent Auger series suggests a phase transition in the $\mathrm{CaO}$ layer, in which a part of $\mathrm{Ca}$ ions is replaced by Mo. A quantitative analysis of the peak intensities indicates the new film stoichiometry to be close to $\mathrm{Ca}_{3} \mathrm{MoO}_{4}$, corresponding to an exchange of $25 \%$ of the $\mathrm{Ca}$ ions. Partial desorption or dewetting of the film is discarded as possible explanation for the modified Auger response, because the $\mathrm{O}$ signal remains almost constant across the transition.

This stoichiometry change is closely connected with the appearance of the $(2 \times 2)$ LEED pattern, reflecting the structural side of the phase transition. The development of the new crystal structure can be monitored via the intensity of the $(2 \times 2)$ superstructure spots measured as a function of temperature [Fig. 2(b)]. The extra spots appear at $900 \mathrm{~K}$, reach their intensity maximum at $1000 \mathrm{~K}$ when the new phase is fully developed, and attenuate above $1100 \mathrm{~K}$ due to film desorption. It should be noted that $\mathrm{MgO}$ films on $\mathrm{Mo}(001)$ do not exhibit a comparable behavior and maintain their structure and stoichiometry until desorption at $1150 \mathrm{~K}$.

To elucidate the nature of the new phase, we have performed DFT calculations on potential Ca-Mo-O structures. We first considered known bulk-phases of the three elements, in particular the $\mathrm{CaMoO}_{3}$ perovskite and $\mathrm{CaMoO}_{4}$ powellite structure with Mo ions sitting in octahedral and tetrahedral positions, respectively. ${ }^{26,27}$ The properties of both phases could not be reconciled with the experimental data for several reasons. First, the size of their basal cells $\left(5.5 \times 5.5 \AA^{2}\right.$ in perovskite and $5.2 \times 5.2 \AA^{2}$ in powellite) is clearly smaller than the $(2 \times 2)$ cell, which makes substantial lattice deformations necessary again. Second, the bulk structures comprise a number of distinguishable layers along their $c$ axis, which should result in different surface terminations but has not been observed experimentally. And third, the high oxygen content of the bulk phases is not compatible with the Auger data obtained for our thin films.

In a next attempt, we have modified the $\mathrm{CaO}$ stoichiometry by removing $25 \%$ of the $\mathrm{Ca}$ or $\mathrm{O}$ ions from the interface plane. The formation of nonstoichiometric interfaces has been suggested as a possible strain-relaxation mechanism for other metal-oxide systems, e.g., $\mathrm{NiO}$ on $\mathrm{Pd}(001) .{ }^{15}$ Our DFT calculations revealed, however, a higher free energy of the $\mathrm{O}$-poor and $\mathrm{Ca}$-poor vacancy structures compared to a strained but stoichiometric $\mathrm{CaO}$ film. While $\mathrm{a} \mathrm{Ca}_{4} \mathrm{O}_{3}$ vacancy structure with a $(2 \times 2)$ cell can be stabilized on $\mathrm{Mo}(001)$ only at very reducing conditions, the oxygen-rich $\mathrm{Ca}_{3} \mathrm{O}_{4}$ phase is always unstable against Mo interdiffusion into the vacancy sites. We

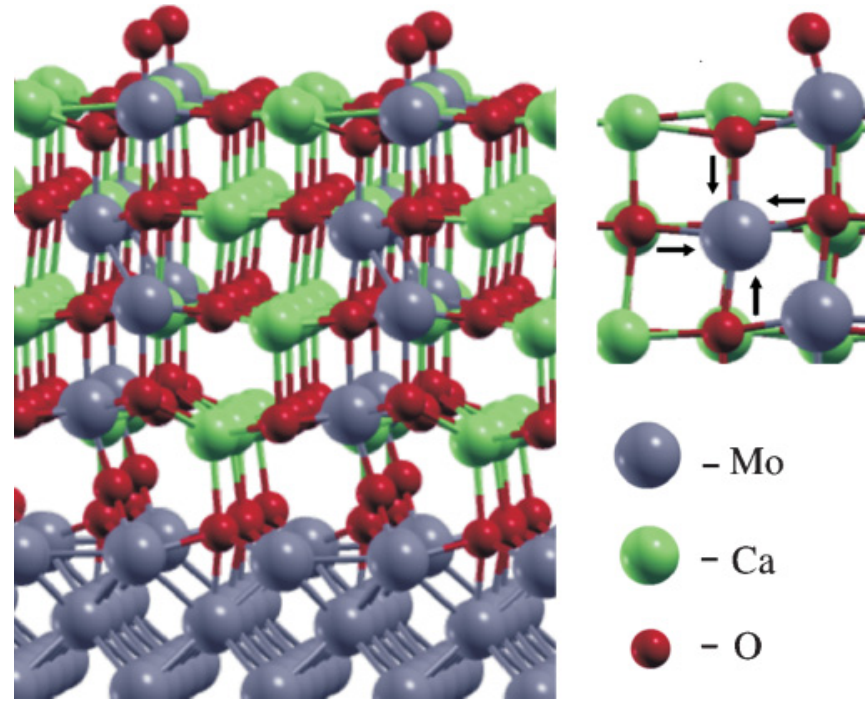

FIG. 3. (Color online) Structure model of a Mo $=\mathrm{O}$ terminated $\mathrm{Ca}_{3} \mathrm{MoO}_{4}$ mixed film with an oxidized Mo plane at the interface to the $\mathrm{Mo}(001)$ support $\left[\mathrm{O} / \mathrm{Ca}_{3} \mathrm{MoO}_{4}(4 L) / \mathrm{O} / \mathrm{Mo}\right.$ phase]. The right panel displays the inward relaxation of $\mathrm{O}$ ions next to a Mo impurity, as marked by small arrows.

note that the instability of vacancy structures is in line with the irreducible nature of $\mathrm{CaO}$.

We therefore favor another model that assumes intermixing of $\mathrm{Mo}$ into the $\mathrm{CaO}$ rocksalt structure, as already suggested by the Auger results. In the model, $25 \%$ of the $\mathrm{Ca}$ ions are replaced by $\mathrm{Mo}$, resulting in a $\mathrm{Ca}_{3} \mathrm{MoO}_{4}$ stoichiometry (Fig. 3). Adjacent $\mathrm{MoO}_{6}$ octahedrons share hereby not more than two oxygen ligands, a constraint that leads to the formation of a $(2 \times 2)$ unit cell. In order to determine the stability of this mixed oxide with respect to a phase-separated $\mathrm{CaO} / \mathrm{Mo}$ reference system, we have calculated the Gibbs free energy $\Delta \gamma$ per surface area $S$ as a function of the oxygen chemical potential $\mu_{O}$ according to $\Delta \gamma(T, p)=$ $\left[G^{\text {mix }}-G^{\text {sep }}-n_{\mathrm{O}} \Delta \mu_{\mathrm{O}}(T, p)\right] / S$. Here, $G^{\text {mix }}$ and $G^{\text {sep }}$ are the free energies of the mixed and the phase-separated system, respectively, being approximated from the total DFT energy at zero $\mathrm{K}$, and $n_{\mathrm{O}}$ is the number of additional oxygen atoms with respect to the reference system. The change in the $\mathrm{O}_{2}$ chemical potential $\Delta \mu_{\mathrm{O}}(T, p)=\mu_{\mathrm{O}}-\frac{1}{2} E\left(\mathrm{O}_{2}\right)$, which we refer to half of the total energy of an oxygen molecule $E\left(\mathrm{O}_{2}\right)$, can be related to temperature $T$ and $\mathrm{O}_{2}$ partial pressure $p .{ }^{28}$ To mimic the experimental situation, the presence of chemisorbed oxygen at the interface and molybdyl $(\mathrm{Mo}=\mathrm{O})$ groups at the surface is considered as well. In all models, the total number of $\mathrm{Ca}$ and Mo atoms is kept constant and only their distribution in the different planes of the slab is altered.

The stability plots for different model structures are shown in Fig. 4. The phase-separated $\mathrm{CaO}(3 L)$ /Mo phase is stable only at extremely oxygen-poor conditions $\left(\Delta \mu_{\mathrm{O}}<-3.1 \mathrm{eV}\right)$. In the range of $-3.1 \mathrm{eV}<\Delta \mu_{\mathrm{O}}<-2.2 \mathrm{eV}$, the most stable phase consists of a three-layer $\mathrm{CaO}$ film grown on an oxidized Mo layer $\left[\mathrm{CaO}(3 L) / \mathrm{O} / \mathrm{Mo}\right.$, while a mixed $\mathrm{Ca}_{3} \mathrm{MoO}_{4}(4 L) / \mathrm{Mo}$ phase is still higher in energy. The formation of surface $\mathrm{Mo}=$ $\mathrm{O}$ groups $\left[\mathrm{O} / \mathrm{Ca}_{3} \mathrm{MoO}_{4}(4 L) / \mathrm{Mo}\right]$ stabilizes the mixed phase, but only at $\Delta \mu_{\mathrm{O}}>-2.2 \mathrm{eV}$ and in presence of chemisorbed 


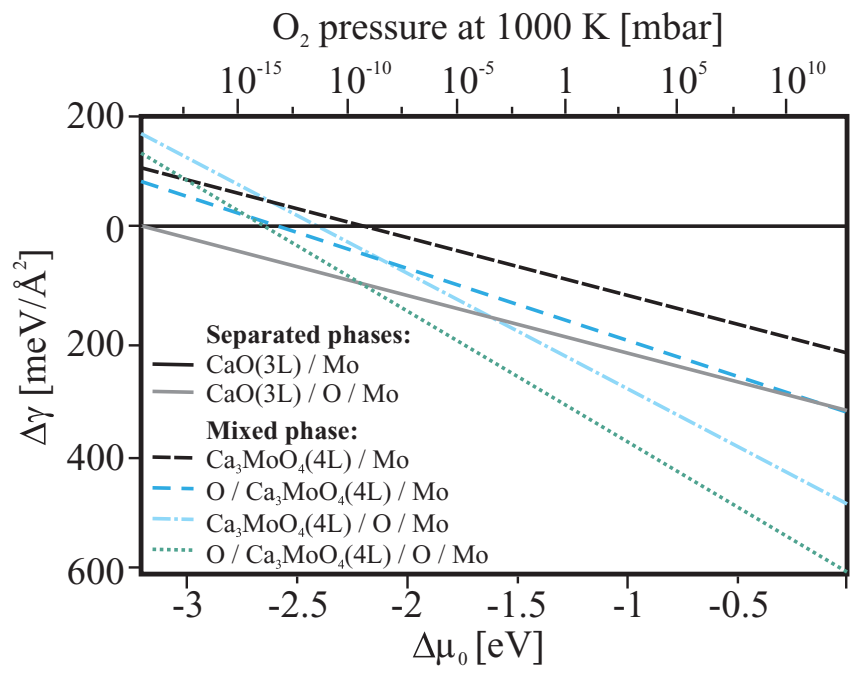

FIG. 4. (Color online) Gibbs-energy change per surface area for the different films considered in the text. The reference system is a three-layer $\mathrm{CaO}$ film grown on $\mathrm{Mo}(001)$. The oxygen chemical potential is converted into an oxygen partial pressure at $T=1000 \mathrm{~K}$ (upper scale).

oxygen at the interface, this phase becomes indeed the most stable one. We note that a simple square arrangement is assumed for the chemisorbed $\mathrm{O}$ ions at the interface, while the exploration of more sophisticated geometries is beyond the scope of this paper. The stability regime of the $\mathrm{O} / \mathrm{Ca}_{3} \mathrm{MoO}_{4}(4 L) / \mathrm{O} / \mathrm{Mo}$ matches the experimental preparation conditions, suggesting that interfacial mixing is indeed thermodynamically favorable. The anticipated formation of $\mathrm{Mo}=$ $\mathrm{O}$ groups that play a crucial role in stabilizing the mixed phase even explains the large corrugation revealed in atomically resolved STM images. While a corrugation of $0.8 \AA$ seems incompatible with a flat (001) rocksalt plane, it perfectly fits into the picture of double-bonded oxygen ions attached to the surface Mo species (1.74 ̊̊ bond length). In fact, a similar surface corrugation has been observed for $\mathrm{V}_{2} \mathrm{O}_{3}(0001)$ covered with $V=$ O groups. ${ }^{3}$

One driving force for the formation of a mixed oxide is certainly the higher oxygen content of the new phase due to oxidation of Mo atoms from the substrate. ${ }^{3,29}$ However, Mo interdiffusion also presents an effective means to release the interfacial strain induced by the deviating $\mathrm{Mo}$ and $\mathrm{CaO}$ lattice parameters. Whereas a metal-oxygen bond length in $\mathrm{CaO}$ is of the order of $2.4 \AA$, it shortens to $1.9 \AA$ in typical Mo-O compounds. A similar trend is revealed for the ionic radii that decrease from $115 \mathrm{pm}$ for $\mathrm{Ca}^{2+}$ to $83 \mathrm{pm}$ for $\mathrm{Mo}^{2+} .30$ Alternating $\mathrm{Ca}$ and $\mathrm{Mo}$ cations in a mixed oxide thus leads to a reduction of the lattice constant, a behavior that was verified with DFT calculations performed on unsupported four-layer-thick slabs. While $\mathrm{CaO}$ has a $(2 \times 2)$ lattice parameter of $6.69 \AA$ (bulk value $6.78 \AA$ ), this value reduces to $6.42 \AA$ for the $\mathrm{Ca}_{3} \mathrm{MoO}_{4}$ film. As a result, the lattice mismatch with the $\mathrm{Mo}(001)$ surface decreases from $8 \%$ to $1.7 \%$, enabling a pseudomorphic growth of the mixed oxide film. The interdiffusion of Mo into the $\mathrm{CaO}$ matrix can thus be considered as "chemical" means to compensate misfit strain in a metal-oxide system.

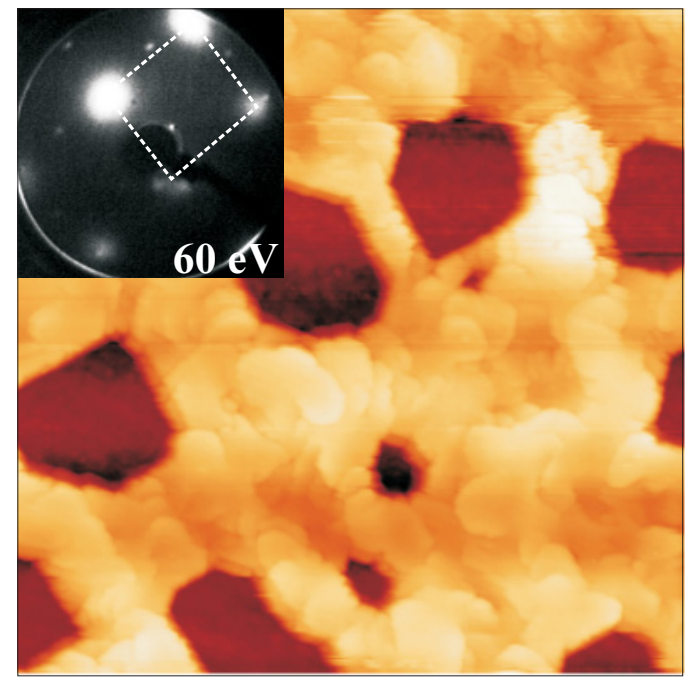

FIG. 5. (Color online) STM image of a 15-ML-thick CaO film deposited onto $\operatorname{Mo}(001)\left(U_{s}=3.6 \mathrm{~V}, I_{t}=25 \mathrm{pA}, 150 \times 150 \mathrm{~nm}^{2}\right)$. The $\mathrm{Ca}_{3} \mathrm{MoO}_{4}$ phase remains visible in the holes of the three-dimensional $\mathrm{CaO}$ patches. The inset shows the corresponding LEED pattern with a $(1 \times 1)$ unit cell.

With the same arguments, the absence of intermixing at the $\mathrm{MgO} / \mathrm{Mo}(001)$ interface can be rationalized. Also here, a mixed $\mathrm{Mg}_{3} \mathrm{MoO}_{4}$ film would be thermodynamically stable with respect to the phase-separated system due to oxidation of extra Mo atoms from the support. However, the stimulus related to misfit strain largely vanishes, as the lattice mismatch decreases only from $5.4 \%$ to $3.8 \%$ when replacing a quarter of the $\mathrm{Mg}$ ions with Mo. Furthermore, Mo diffusion inside a dense $\mathrm{MgO}$ lattice might be harder than in the more spacious $\mathrm{CaO}$ structure. We note, however, that substantial quantities of Mo have been detected with electron-paramagnetic resonance spectroscopy in Mo-supported $\mathrm{MgO}$ films treated at high temperature, suggesting that the formation of a mixed $\mathrm{Mg}-\mathrm{Mo}$ oxide might be mainly kinetically hindered. ${ }^{31}$

For the same kinetic reasons, the formation of a mixed Ca-Mo oxide film is restricted to a region close to the metaloxide interface. Even for annealing temperatures as high as $1000 \mathrm{~K}$, the Mo supply from the support will stop at a critical film thickness due to the low diffusion rates. We indeed observe a self-terminating growth of the mixed oxide film. Beyond 4-5-ML nominal thickness, three-dimensional islands develop on top of the surface, which display the typical LEED and Auger signature of pristine rocksalt $\mathrm{CaO}$ (Fig. 5). With the absence of Mo in the film, also the lattice mismatch with the substrate appears again, driving the system into a 3D VolmerWeber mode.

\section{CONCLUSION}

We have demonstrated that interdiffusion of substrate ions into a thin oxide film is an effective means to release the lattice strain imposed by the support. The mechanism becomes active in compressively strained oxides if the substrate ions occupy less space than the intrinsic cations of the film. This is the case for $\mathrm{CaO}$ deposited onto $\mathrm{Mo}(001)$ and gives rise to the formation of well-ordered, atomically flat $\mathrm{Ca}_{3} \mathrm{MoO}_{4}$ films at high temperature. A similar behavior might also be expected 
for films under tensile strain, when structural relaxation is realized by the interdiffusion of larger ions from the support. Intermixing is not observed for metal-oxide systems below a critical lattice mismatch, as demonstrated for $\mathrm{MgO}$ films on $\mathrm{Mo}(001)$ in this study. The strain-induced formation of mixed-oxide structures provides insight into the characteristic of oxide growth on metal surfaces and might explain several yet unsolved growth phenomena. Moreover, interfacial strain might be exploited to prepare mixed-oxide films with extremely high structural quality, in particular if a simple co-deposition of the constituents does not yield the desired structures.

\section{ACKNOWLEDGMENTS}

The support of the COST Action D41 and the Regione Lombardia and CILEA Consortium through a LISA Initiative are gratefully acknowledged. *nilius@fhi-berlin.mpg.de

†gianfranco.pacchioni@unimib.it

${ }^{1}$ S. A. Chambers, Surf. Sci. Rep. 39, 105 (2000); C. C. Chusuei, X. Lai, K. Luo, and D. W. Goodman, Top. Catal. 14, 71 (2001).

${ }^{2}$ M. Bäumer and H.-J. Freund, Prog. Surf. Sci. 61, 127 (1999).

${ }^{3}$ S. Surnev, M. G. Ramsey, and F. P. Netzer, Prog. Surf. Sci. 73, 117 (2003).

${ }^{4}$ H.-J. Freund and G. Pacchioni, Chem. Soc. Rev. 37, 2224 (2008).

${ }^{5}$ G. Pacchioni, L. Giordano, and M. Baistrocchi, Phys. Rev. Lett. 94, 226104 (2005).

${ }^{6}$ C. Noguera and J. Goniakowski, J. Phys.: Condens. Matter 20, 264003 (2008).

${ }^{7}$ L. Giordano, G. Pacchioni, J. Goniakowski, N. Nilius, E. D. L. Rienks, and H.-J. Freund, Phys. Rev. B 76, 075416 (2007); N. Nilius, E. D. L. Rienks, H.-P. Rust, and H.-J. Freund, Phys. Rev. Lett. 95, 066101 (2005).

${ }^{8}$ U. Martinez, L. Giordano, and G. Pacchioni, Chem Phys Chem 11, 412 (2010).

${ }^{9}$ Y. N. Sun, L. Giordano, J. Goniakowski, M. Lewandowski, Z. H. Qin, C. Noguera, S. Shaikhutdinov, G. Pacchioni, and H. J. Freund, Angew. Chem. Int. Ed. 49, 4418 (2010).

${ }^{10}$ S. A. Chambers, T. T. Tran, T. A. Hileman, and T. A. Jurgens, Surf. Sci. 320, L81 (1994).

${ }^{11}$ J. Goniakowski and C. Noguera, Interface Sci. 12, 93 (2004).

${ }^{12}$ L. Giordano, F. Cinquini, and G. Pacchioni, Phys. Rev. B 73, 045414 (2006).

${ }^{13}$ J. Wollschläger, D. Erdos, H. Goldbach, R. Hopken, and K. M. Schröder, Thin Solid Films 400, 1 (2001); J. Schoiswohl, W. Zheng, S. Surnev, M. G. Ramsey, G. Granozzi, S. Agnoli, and F. P. Netzer, Surf. Sci. 600, 1099 (2006).

${ }^{14}$ S. Benedetti, H. M. Benia, N. Nilius, S. Valeri, and H.-J. Freund, Chem. Phys. Lett. 430, 330 (2006); S. Benedetti, P. Torelli,
S. Valeri, H. M. Benia, N. Nilius, and G. Renaud, Phys. Rev. B 78, 195411 (2008).

${ }^{15}$ S. Agnoli, M. Sambi, G. Granozzi, A. Atrei, M. Caffio, and G. Rovida, Surf. Sci. 576, 1 (2005).

${ }^{16}$ G. Kresse, M. Schmid, E. Napetschnig, M. Shishkin, L. Kohler, and P. Varga, Science 308, 1440 (2005).

${ }^{17}$ H. Gabasch, W. Unterberger, K. Hayek, B. Klotzer, G. Kresse, C. Klein, M. Schmid, and P. Varga, Surf. Sci. 600, 205 (2006).

${ }^{18}$ Q. H. Wu, A. Fortunelli, and G. Granozzi, Int. Rev. Phys. Chem. 28, 517 (2009).

${ }^{19}$ C. Tusche, H. L. Meyerheim, and J. Kirschner, Phys. Rev. Lett. 99, 026102 (2007).

${ }^{20}$ G. Kresse and J. Hafner, Phys. Rev. B 47, 558 (1993); G. Kresse, and J. Furthmüller, ibid. 54, 11169 (1996).

${ }^{21}$ J. P. Perdew, J. A. Chevary, S. H. Vosko, K. A. Jackson, M. R. Pederson, D. J. Singh, and C. Fiolhais, Phys. Rev. B 46, 6671 (1992).

${ }^{22}$ P. E. Blöchl, Phys. Rev. B 50, 17953 (1994).

${ }^{23}$ O. Bengone, M. Alouani, P. Blöchl, and J. Hugel, Phys. Rev. B 62, 16392 (2000).

${ }^{24}$ H. M. Benia, P. Myrach, N. Nilius, and H.-J. Freund, Surf. Sci. 604, 435 (2010).

${ }^{25}$ C. Noguera, J. Godet, and J. Goniakowski, Phys. Rev. B 81, 155409 (2010).

${ }^{26}$ O. Y. Gorbenko, S. V. Samoilenkov, I. E. Graboy, and A. R. Kaul, Chem. Mater. 14, 4026 (2002).

${ }^{27}$ W. S. Cho, M. Yashima, M. Kakihana, A. Kudo, T. Sakata, and M. Yoshimura, J. Am. Ceram. Soc. 80, 765 (1997).

${ }^{28}$ K. Reuter and M. Scheffler, Phys. Rev. B 65, 035406 (2001).

${ }^{29}$ C. Dri, C. Africh, F. Esch, G. Comelli, O. Dubay, L. Koehler, F. Mittendorfer, G. Kresse, P. Dudin, and M. Kiskinova, J. Chem. Phys. 125, 094701 (2006).

${ }^{30}$ CRC Handbook of Chemistry and Physics, edited by D. R. Lide (CRC Press, Boca Raton, 2010).

${ }^{31}$ A. Gonchar, PhD Thesis, TU Berlin, Berlin, 2011. 